\title{
Extraterritorialidade e Modernidade na Literatura Hispano-Americana: - caso de Octavio Paz
}

\author{
Robson Batista dos Santos Hasmann \\ Mestre em Letras pelo Programa de Língua Espanhola e Literaturas \\ Espanhola e Hispano-americana da FFLCH-USP. Professor de Espanhol do \\ Instituto Federal de Educação, Ciência e Tecnologia de São Paulo.
}

Resumo: Em Extraterritorial (2002), George Steiner problematiza a relação que alguns escritores estabelecem com línguas não maternas e a forma como esse contato pode enriquecer suas obras. $\mathrm{O}$ crítico levanta algumas questões a partir da língua inglesa promovendo desenvolvimento estético em autores como Nabokov e Beckett. Dentre os escritores hispânicos, Steiner coloca o exemplo de Jorge Luis Borges. Esse fenômeno observado por Steiner encontra paralelos com as reflexões do poeta e ensaísta mexicano Octavio Paz sobre a modernidade, especificamente nos ensaios "¿Es moderna nuestra literatura?” (1990a) e "Alrededores de la literatura hispanoamericana" (1990a). O que aproxima os conceitos de extraterritorialidade e modernidade é justamente o deslocamento entre países e a aquisição de outra língua decorrente do trânsito territorial. A partir da discussão desses dois conceitos, o artigo investiga alguns aspectos da poesia e da ensaística do próprio Octavio Paz.
AвSTRACT: In Extraterritorial (2002), George Steiner questions the relationship that some writers establish with no maternal languages and how this contact can enrich their works. The critic raises some questions from the English language promoting aesthetic development in authors such as Nabokov and Beckett. Among Hispanic writers, Steiner shows the example of Jorge Luis Borges. This phenomenon observed by Steiner is similar to the reflections about modernity of the Mexican poet and essayist Octavio Paz, specifically in the essays " ¿Es moderna nuestra literatura?" (1990a) and "Alrededores de la literaturea hispanoamericana" (1990a). What approaches the concepts of extraterritoriality and modernity is precisely the displacement between countries and the acquisition of another language arising from transit planning. From the discussion of these two concepts, the paper investigates some aspects of the poetry and essays of Octavio Paz himself.

\section{Jntroduçåo}

El ingreso de los jóvenes españoles [en la revista Taller] no fue sólo una definición política sino histórica y literaria. Fue un acto de fraternidad pero también fue una declaración de principios: la verdadera nacionalidad de un escritor es su lengua.

Octavio Paz, In: "Razón de ser"

Em Extraterritorial: ensayos sobre literatura y la revolución del lenguaje (2002), George Steiner faz reflexões instigantes acerca da relação que os escritores têm com 
a língua. No ensaio inicial, que dá título à obra, "Extraterritorial”, o crítico cita vários autores, de diversas nacionalidades, cuja produção literária se constrói numa relação interlinguística, ou seja, entre línguas diferentes.

O que os autores ${ }^{1}$ mencionados pelo crítico têm em comum é o fato de usarem em sua literatura uma língua com substrato em outra; ou deslocarem-se de uma língua para outra, de maneira natural. As causas para esses deslocamentos estariam em diversos fatores, notadamente, o exílio. A escrita em outra língua, portanto, constituir-se-ia como uma das principais características de adaptação para o refugiado ou o exilado. Com efeito, Steiner afirma que, no mundo contemporâneo (o ensaio é de 1969), "Nos parece adecuado que los que producen arte en una civilización casi bárbara, que ha despojado de su hogar a tantas personas y arrancado lenguas y gente de cuajo, sean también poetas sin casa, vagabundos atravesando diversas lenguas”(p. 24).

É importante destacar que a condição de extraterritorial está relacionada a um bilinguismo ou um multilinguismo. No entanto, o caráter bilíngue ou multilíngue, segundo o crítico procura postular, apresenta-se diferentemente de quando as línguas nacionais ainda não haviam se constituído totalmente. Aliás, Steiner (p.18) afirma que "el bilingüismo, en el sentido de la capacidad de expresarse con fluidez en la propia lengua y en latín y/o francés, era la regla más que la excepción en las elites europeas hasta fines del siglo XVIII." Consequentemente, "para que el escritor se convirtiera bilingüe o multilingüe ${ }^{2}$ en el sentido moderno, tenían que ocurrir verdaderos cambios en su sensibilidad y estatus personal”.

Quase todos os exemplos de escritores extraterritoriais trabalhados pelo crítico transitam pela língua inglesa, seja ela língua primeira ou segunda. Porém, as ideias possibilitam pensar a situação de escritores latino-americanos. Isso porque as discussões acerca de (e a idealização por) uma unidade latino-americana fazem parte de pensamentos de diversos intelectuais e artistas em diferentes momentos da história do continente. Da mesma forma, a tentativa dos literatos de romperem com as formas europeias de literatura é parte constitutiva dessas discussões.

Partindo dessas preocupações, se considerada a situação das línguas espanhola, inglesa e portuguesa (e consequentemente a literatura produzida por elas), ver-se-á que uma característica comum e significativa a todas é o trânsito de continentes e a constante mescla com outras línguas "originais” dos lugares às quais foram levadas.

Essa problemática, já tratada de diversas perspectivas nos estudos latino-americanos, será explorada neste trabalho a partir das ideias discutidas por Octavio Paz nos ensaios "Alrededores de la literatura hispanoamericana”, “¿Es moderna nuestra literatura?" e o de maior fôlego Los hijos del limo. Ao mesmo tempo, recortou-se do imenso universo americano um autor que, sob a perspectiva abordada, representaria

É o caso, por exemplo, de Nabokov, Heine, Oscar Wilde, Beckett e, no âmbito da literatura hispano-americana, Borges.

Portanto, extraterritorial. 
sobremaneira a situação e o papel da literatura e do literato latino-americano de língua espanhola: o próprio Octavio Paz.

Com efeito, o objetivo é compreender as propostas do autor mexicano sobre a literatura na América Latina, tomando-o como eixo das discussões. A fim de operacionalizar a compreensão, algumas reflexões de Paz sobre a Modernidade serão contrapostas ao conceito de extraterritorialidade desenvolvido por George Steiner.

\section{extraterritorialidade do escritor latino-americano}

Em Los hijos del limo (1974), ensaio que se configura como uma ampliação das discussões em El arco y la lira, e cujo propósito é percorrer a história da poesia moderna (do Romantismo à Vanguarda), a questão do deslocamento territorial e linguístico aparece fortemente apresentado como uma das principais marcas dos escritores modernos. A visão de Octavio Paz sobre a poesia em língua espanhola na América merece atenção especial, ainda que pareça extensa a citação:

Hay una curiosa semejanza entre la historia de la poesía moderna en castellano y en inglés: angloamericanos e hispanoamericanos dejan casi en los mismos años su tierra natal; asimilan en Europa las nuevas tendencias, las transforman y la recrean; saltan dos formidables obstáculos (los Pirineos y el Canal de la Mancha); irrumpen en Madrid y Londres; despiertan a los amodorrados poetas ingleses y españoles; los innovadores (Pound y Huidobro) son acusados de herejías galicistas y cosmopolitas; al contacto de las nuevas tendencias dos grandes poetas de la generación anterior (Yeats y Jiménez) se desnudan de sus vestiduras simbolistas y escriben al final de su vida sus mejores poemas; el cosmopolitismo de Williams y el de Vallejo. (PAZ, 1974, p. 182)

Essa atitude de deixar a terra natal, a cidade e o país é o que marca também a concepção extraterritorial de George Steiner. Segue-se ao deslocamento entre países uma mudança de atitude: a assimilação das tendências europeias passa pela transformação e recriação da língua. Com efeito, há um enriquecimento da linguagem a tal ponto que a literatura hispano-americana passa a impactar a espanhola.

Como o propósito deste trabalho é a reflexão sobre os autores latino-americanos, cabe examinar mais de perto o que Steiner diz sobre um deles, Jorge Luis Borges, cuja extraterritorialidade dá-se, por assim dizer, em outro nível. Assim se expressa o crítico sobre o escritor argentino:

Aun cuando, por lo que sé, Borges solo escribió poemas o relatos en español, es uno de los nuevos “esperantistas”. Su conocimiento del francés, el alemán y, especialmente, el inglés es profundo. Muy frecuentemente, un texto inglés - Blake, Stevenson, Coleridge, 
De Quincey - subyace en su frase española. La otra lengua se ‘trasluce’ confiriéndole a los versos de Borges y a sus Ficciones una cualidad luminosa y universal. Borges se sirve de la lengua vernácula de Argentina y de su mitología para conferir peso a lo que de otra manera sería una imaginación demasiado abstracta, demasiado arbitraria. (STEINER, p. 20)

Como se percebe, o que Steiner aponta como marca de extraterritorialidade em Borges seria a presença do inglês em seu espanhol, ou seja, o inglês subjazendo ao espanhol. Por outro lado, em todo o trecho, talvez a afirmação que mais convide à reflexão seja a referência à "universalidade” de Borges. Neste ensaio, Jorge Luis Borges é pensado en passant. Por seu caráter ensaístico, o texto de Steiner não aprofunda a discussão, nem desenvolve o que seria a "universalidade" em um escritor, muito menos em Borges. No entanto, a posição universalista (portanto extraterritorial) do escritor argentino é explorada mais profundamente no ensaio, presente no mesmo livro, intitulado "Los tigres en el espejo". Nele, Steiner defende que a universalidade de Borges poderia ser explicada por sua educação, sobretudo nos anos que vão de 1914 a 1921, nos quais viveu na Suíça, na Itália e na Espanha (STEINER, 2002, p. 38-39).

Relacionando o que foi apontado inicialmente sobre as "autenticas alteraciones de sensibilidad y condición personal” (STEINER, p. 18) que foram necessárias para que os escritores citados por Steiner (Heine, Beckett, Oscar Wilde e Nabokov) recebessem o epíteto de extraterritoriais, verifica-se que, paralelamente, os autores hispanoamericanos que mais fortemente marcaram a literatura no século XX (Huidobro, Borges, Maples Arce, Pablo Neruda, Octavio Paz etc.) têm em comum o fato de terem promovido mudanças na linguagem, as quais seriam decorrentes de uma mudança de atitude. Seja o exílio, seja o caráter revolucionário contra a geração e a estética anteriores, a situação de imigração possibilitou à literatura americana de expressão castelhana enriquecer-se de tal maneira que chegou a impactar a literatura espanhola. Assim, é importante pensar como, na modernidade, a língua espanhola foi recriada para que a expressão poético-literária desse conta da nova visão de mundo e da nova atitude. É justamente essa alteração “de sensibilidade e condição pessoal”, nas palavras de Steiner, uma das principais marcas que, como tentarei mostrar mais adiante, configuram a concepção de Octavio Paz sobre o moderno e a modernidade.

Para tal, destaca-se inicialmente que a relação entre língua e produção literária, como bem marca Steiner na abertura do ensaio, não foi um acontecimento fortuito com os autores citados nem algo iniciado por eles.

Língua, cultura e produção literária sempre estiveram juntas. Essa relação é pensada, um pouco mais detidamente, por Octavio Paz em vários ensaios e obras. Em Traducción: literatura y literariedad (1990b), Paz postula que "aprender a hablar es aprender a traducir” (p. 9). Com efeito, um povo, frente à língua de outro (e do Outro) e ao assombro que ela causa, não tem outra saída que se lançar na busca de uma 
resposta que possibilite a organização de um sentido. A tradução, por exemplo, era vista na Antiguidade como a garantia do espírito de que a confusão gerada pelo primeiro contato iria se dissipar. Entretanto, "la Edad Moderna destruyó esa seguridad" (p. 10). A destruição foi consequência do redescobrimento da "infinita variedad de los temperamentos y pasiones” (p. 10) particulares e da evolução de meios tecnológicos e de produção.

Assim, dentro deste trabalho, entende-se que esse Outro de que fala Octavio Paz seria o mundo tecnológico, que as formas vanguardistas do início do século XX tentaram compreender e representar. Há que se pensar, ainda, no caminho inverso que a arte buscou: uma imersão na subjetividade e no mundo onírico. Com efeito, a busca por novas formas de expressão que conseguissem representar um mundo contrário àquele visto na realidade empírica e na expressão artística americanas pode ser interpretada como esse Outro que assombra e ao qual o poeta quer se aproximar para dar sentido ao mundo. Essa problemática (a nova sensibilidade modificada pelas novas visões do mundo e a busca por compreender o que se vê e por negar as expressões tradicionais de escrita), que é vista de maneira ampla, toma conta da estética vanguardista hispano-americana.

Com efeito, é pertinente enfatizar os casos exemplares estudados por Steiner e Paz. Para o primeiro, escritores como Jorge Luis Borges têm uma profunda intimidade com o inglês e isso possibilita que ele "transpareça" (aspas do original) "Confiriéndole a los versos de Borges y a sus Ficciones una cualidad luminosa y universal” (STEINER, p. 20). Por sua vez, Octavio Paz apresenta diversos autores para comprovar que o trânsito entre línguas é sempre possível e, sobretudo, enriquecedor não apenas para a escrita individual, mas para toda a literatura. Dentre esses diversos autores, cita dois, como contraponto. O primeiro é Miguel de Unamuno, para quem haveria uma intraduzibilidade da língua espanhola. Considerando os versos do poeta e ensaísta espanhol como um impulso lírico-patriótico, Paz ironiza que "Es curioso [...] que la intraducible esencia de España consista en una sucesión de nombres romanos, árabes, celtiberos y vascos” (PAZ, 1990b, p. 16). ${ }^{3}$ O segundo autor citado por Paz é o franco-uruguaio Jules Laforgue, cuja fortuna "en la poesía inglesa y en la lengua española es un ejemplo de la interdependencia entre creación e imitación, traducción y obra original” (PAZ, 1990b, p. 26). Na poesia hispano

O poema citado por Paz é o seguinte:

Avila, Málaga, Cáceres,

Játiva, Mérida, Córdoba,

Ciudad Rodrigo, Sepúlveda,

Ubeda, Arévalo, Frómista,

Zumárraga, Salamanca,

Turéngano, Zaragoza,

Lérida, Zamarramala,

sois nombres de cuerpo entero,

libres, propios, los de nómina,

el tuétano intraducible

de nuestra lengua española. 
- americana, marcas da poesia de Laforgue aparecem, por exemplo, em Leopoldo Lugones, sobretudo em Los crepúsculos del jardín.

Essa busca por uma expressão que manifeste o novo e que é potencializada por contatos culturais pode ser vista, ainda, em dois manifestos da vanguarda hispano -americana: o de Maples Arce e de Vicente Huidobro ${ }^{4}$. Em la Hoja de Vanguardia no 1, publicada em 1923, Manuel Maples Arces assim postula a necessidade de cortar a corrente quando os meios de expressão chegam à inabilidade e à insuficiência na tradução de emoções pessoais. No mesmo manifesto, convoca: "cosmopoliticémonos”. Telégrafos, arranha-céus, elevadores, locomotivas, chaminés de fábricas, bem como aproximações culturais povoam o manifesto e fazem com que o poeta tenha consciência de que "las únicas fronteras posibles en arte son las propias infranqueables de nuestra emoción marginalista” (p. 91). Os manifestos vanguardistas de Maples Arce são contra a arte tradicional e a burguesia incentivadora de uma postura política e artística ausente de crítica. Do mesmo modo, Vicente Huidobro, em 1925, ao organizar o Creacionismo ${ }^{5}$, defende que um poema concebido dentro dessa estética apresentaria um novo fato ao leitor, algo jamais visto, mas que seria desejado. Ainda sobre o poeta chileno, cabe destacar as palavras de Octavio Paz em Los hijos del limo. Para ele, Ecuatorial e Poemas árticos, os primeiros livros de Huidobro, são os iniciadores da vanguarda em castelhano. Os livros, que foram publicados em 1918, logo depois de Huidobro ter passado por Paris e Madri, em 1916, teriam uma expressão “do ar”, no sentido de que há um caráter imensamente internacional. Como é sabido, Huidobro movia-se do espanhol para o francês e vice-versa de maneira que uma língua enriquecia linguagem da outra ${ }^{6}$.

Por outro lado, é necessário lembrar que o contato com outras línguas e literaturas não gerou, nos movimentos de vanguarda, apenas uma transplantação da linguagem dos países com os quais os autores tiveram contato. Octavio Paz, em Los hijos del limo (p. 131), explica que "El cosmopolitismo [dos poetas modernistas - e, por conseguinte, dos vanguardistas] los hizo descubrir otras literaturas y revalorar nuestro pasado indígena”. Nesse sentido, percebe-se uma tensão entre um cosmopolitismo e o americanismo, que se são acentuados nas vanguardas, não são, contudo, novos na literatura hispano-americana. Isso porque essa tensão aparece, mais remotamente, na poesia de Sor Juana Inés de Cruz. Para Octavio Paz (1974), o primeiro poema cosmopolita da literatura hispano-americana é “El sueño”, de 1692, mais tarde renomeado como "Primero sueño". Nesse poema, o cosmopolitismo estaria marcado por dois aspectos: 1) a presença de várias línguas: latim, castelhano, náuatle, português e os dialetos populares indígenas, mestiços e mulatos; e 2) uma tensão entre linguagem culta e coloquial.

\footnotetext{
Tanto a Hoja de Vanguardia quanto o manifesto "El creacionismo” foram lidos a partir de Hugo J. Verani, constante nas referências ao final A primeira publicação foi em francês.

É o caso de "O homem alegre”, cuja primeira versão está em espanhol, a segunda em francês e a terceira novamente em espanhol. Sugiro, ainda, o artigo "El bilingüismo como factor creativo em Altazor", de Magdalena García Pinto.
} 
Ao considerar as mudanças ocorridas na literatura hispano-americana, vale pensar, também, as alterações proporcionadas pelo Modernismo, e dele para as Vanguardas. Essas mudanças não estavam relacionadas apenas aos valores estéticos e sociais, mas a posturas diferentes: "El modernismo había poblado el mar de tritones y suenas; los nuevos poetas viajan en barcos comerciales y desembarcan, no en Cíteres, sino en Liverpool” (PAZ, 1974, p. 136-137). A partir do apresentado infere-se que, na literatura hispano-americana, o momento que melhor potencializaria uma visão extraterritorial dos escritores hispânicos está fortemente marcado pelo Modernismo e pelas vanguardas. À diferença do primeiro, no entanto, a Vanguarda propôs não apenas uma nova forma de olhar o mundo, mas também uma negação do modo antigo de vê-lo. Maples Arce, por exemplo, afirmará que "Un arte nuevo [...] requiere una sintaxis nueva” (p. 92).

Essa dialética entre a continuidade da tradição literária e da ruptura com essa tradição na literatura hispano-americana será explorada por Octavio Paz para caracterizar a modernidade na América espanhola. Ele identifica a literatura hispano-americana como parte de um processo repleto de nuances e continuidades. Herdeiras da arte romântica, as vanguardas seriam uma continuidade do desejo de libertação do espírito e, consequentemente, da expressão poética.

Suas observações, seus postulados, suas críticas acerca da modernidade estão dispersos em muitos textos e se cristalizam nos diversos ensaios de Los hijos del limo. No que tange exclusivamente à literatura hispano-americana, como apontado no início, destacam-se dois ensaios: “ ¿Es moderna nuestra literatura?” e "Alrededores de la literatura hispanoamericana".

No primeiro, o ensaísta parte do princípio de que a literatura ocidental não é una, mas sim un todo. Com efeito, a literatura hispano-americana é uma parte dentro desse todo, já que as unidades (literatura inglesa, alemã, italiana etc.) estão numa “continua relación con las otras” (p. 39). É dessa contínua relação com as outras que surge a pergunta que dá título ao ensaio. A concepção de moderno se dará, enfim, pelo modo como, ao longo da história, se constituiu a relação entre essas unidades e, claro, a literatura hispano-americana.

Já o segundo ensaio é também transpassado pelo conceito de modernidade. Depois de tentar marcar uma palavra que melhor definiria o continente americano colonizado por Espanha e Portugal, Octavio Paz afirma, a propósito da relação língua e literatura: ainda que não exista povo sem literatura, "el destino final de todas las literaturas [es] ser obras vivas escritas en lenguas muertas" (PAZ, 1990b, p. 26).

Línguas mortas? O ensaísta não continua desenvolvendo a ideia. Nesse momento, se detém na relação que os americanos tiveram com a língua de seus colonizadores: as línguas portuguesa, espanhola e inglesa. Ele se pergunta: Que língua foi a matéria que deu forma à literatura latino-americana? Embora possa parecer óbvia a resposta de que a foi a língua espanhola, não é menos clara a ideia de que essa língua não era a 
utilizada por Quevedo, Góngora ou Cervantes. Isso porque “en general, la vida de una literatura se confunde con la de la lengua en que está escrita; en el caso de nuestra [a da América española] literatura, su infancia coincide con la madurez de la lengua” (p. 28). Octavio Paz avança a discussão mostrando como a literatura hispano-americana, em seus primeiros séculos, é herdeira da espanhola. Sor Juana Inés de la Cruz, por exemplo, representaria não o início de uma nova forma estética, mas sim a herança de uma língua já madura.

Por tudo o que se expôs até agora sobre a literatura hispano-americana, é possível aproximar-se do conceito que George Steiner postula sobre território. A língua espanhola, levada a outro continente, com o tempo, sem deixar de ser o que era (foi) chega a ser outra. Em outras palavras, pode-se dizer que a língua que cruzou o Atlântico é reterritorializada nas obras dos escritores em fins do século XIX e XX. Ainda que herdada, a língua espanhola faz parte de outra forma de viver e experimentar o tempo e a realidade, ou seja, a relação entre língua e cultura se faz diferente daquela dos primeiros momentos de colonização.

Essa relação língua-cultura e mudança de postura frente à sociedade e a tradição é exemplarmente explorada por Jorge Schwartz (1995). Com uma perspectiva histórica dos movimentos de Vanguarda, o crítico apresenta diversos momentos da história latino-americana e afirma que o desejo por constituir uma linguagem diferente daquela que chegou com os países descobridores não é própria da vanguarda. Para ele, "los movimientos de renovación lingüística retoman una cuestión que surge con ímpetu en el romanticismo, como consecuencia ideológica de las guerras de independencia" (SCHWARTZ, 1995, p. 33), tanto na América espanhola quanto na portuguesa.

Pelo exposto acerca do deslocamento físico e, consequentemente, do linguístico, é possível afirmar que, se para Steiner o território pode ser entendido como a língua, onde quer que esteja o sujeito-escritor, para Paz, viver a língua em outro espaço físico permitirá mudanças: é o surgimento da linguagem. Portanto, um eixo comum que se pode deduzir é que o deslocamento físico e o contato com outras culturas (algo que sempre existiu, mas foi ampliado na Modernidade) implicam uma transformação da língua "original” em novas formas estéticas que, na América aliou-se, sobretudo, com as vanguardas, ocasionando uma ruptura com expressões e visões antigas de mundo.

\section{Octavio Paz: escritor extraterritorial?}

A partir da constatação de que o conceito de extraterritorialidade de George Steiner e as reflexões de Octavio Paz sobre a Modernidade na América espanhola têm pontos em comum, o interesse agora é procurar situar o autor mexicano em sua extraterritorialidade. Nesse sentido, o interesse neste ponto do trabalho está em identificar como a literatura de Octavio Paz, em sua singularidade (a língua espanhola 
e a cultura mexicana) possui caráter universal, no sentido em que foi apresentada a concepção de extraterritorialidade a respeito do escritor hispano-americano. Com efeito, identificada a universalidade, será possível verificar também em que medida se dá a continuidade com uma tradição literária imediatamente anterior a ele (as vanguardas) ou a ruptura com ela.

Poder-se-ia, de início, opor-se ao caráter extraterritorial de Octavio Paz, já que grande parte de sua obra é conhecida sobretudo pela escrita e publicação em espanhol ${ }^{7}$. No entanto, há alguns fatores contrários a considerar que permitem problematizar essa oposição. O primeiro é que há um "outro nível de extraterritorialidade”, tal como pensa Steiner sobre Borges. Em outras palavras, ser extraterritorial não significaria apenas a transição entre línguas ou a autotradução. Além disso, ainda estabelecendo o paralelo com Borges, vale destacar a educação que Octavio Paz recebeu nos Estados Unidos. Outro fator é que Octavio Paz não produziu, sempre, sua obra no México. Sua movimentação por diversos países permitiu-lhe construir uma literatura universal. Muitos de seus ensaios são reformulações de conferências e palestras feitas em universidades estrangeiras. O livro de ensaios Los hijos del limo é ilustrativo desse processo. No prefácio à segunda edição, lê-se: "El texto de este livro es, modificado y ampliado, el de las conferencias que di en la Universidad de Harvard (Charles Eliot Norton Lectures) el primer semestre de 1972”. Assim é que, observando a biografia de Octavio Paz, rapidamente se reconhece que a mobilidade entre diversos países marcará fortemente sua obra. Manuel Ulacia (1999, p. 13), ao identificar "etapas criativas” na obra paziana, leva em consideração na divisão os locais onde esteve ou por onde passou o poeta. A primeira etapa, entre os anos de 1931 e 1943, está relacionada com a experiência de Paz como estudante do ensino secundário. Há que se destacar, ainda, o contato do escritor com autores espanhóis da Geração de 27. Rafael Alberti terá uma estância na Cidade do México e proporcionará a Paz um contato mais intenso com autores como Gôngora e Neruda (a quem o mexicano ainda não conhecia). Nesses anos ainda é marcante a leitura atenta de Ortega y Gasset. Enfim, nesses anos iniciais da formação poética a extraterritorialidade de Octavio Paz está marcada pelo deslocamento de autores europeus para a América - atitude e relacionamento que serão intensificados pela presença de surrealistas franceses durante os anos da segunda guerra mundial.

Já a segunda etapa (1943 a 1960) é marcada pelas viagens aos Estados Unidos, Japão e Índia, até a volta ao México. Nesse momento, os anos de 1943 a 1945 são significativos. Ao receber uma bolsa de estudos Guggenheim, o poeta mexicano se dedica à obra de T.S. Eliot, Ezra Pound, E.E. Cumings e Stevens, bem como

Estudo interessantíssimo ainda por ser feito seria uma comparação das versões em francês e espanhol de El mono gramático, uma vez que o livro foi escrito originalmente em francês. 
trava contato pessoal com Williams Carlos Williams, que terá poemas traduzidos e publicados por Paz em Versiones y diversiones. Ainda nesses anos, terminada a guerra, é designado a viver em Paris como representante da diplomacia mexicana. Nesse momento, se aproxima do grupo de André Breton.

Uma terceira etapa, que seria experimentada entre 1961e 1968, está ligada ao extenso período que passou novamente na França e como embaixador na Índia, até sua desvinculação oficial do Governo após os acontecimentos de Tlateloco. Já em 1969, período correspondente à quarta etapa criativa, há uma “peregrinação” pela Ingleterra e novamente aos Estados Unidos como professor. Uma última etapa não explorada por Ulacia é aquela que será identificada com a criação de ideogramas, momento em que chega a dialogar, inclusive, com os poetas concretistas no Brasil ${ }^{8}$.

Dentro dessas etapas, são constantes as reflexões mítica, política, social, histórica, poética etc. a partir da língua.

Na primeira etapa, por exemplo, há uma tentativa de aproximação com a produção vanguardista, sobretudo com autores como os poetas Carlos Pellicer e Xavier Villaurutia. A exploração da língua sendo a principal motivação para a produção artística e política intensifica-se quando o poeta, nas décadas de trinta e quarenta, tem contato com os surrealistas franceses, sobretudo André Breton.

Nos ensaios de El laberinto de la soledad, publicado inicialmente em 1950, em que o autor se propõe uma compreensão de uma possível "mexicanidade" são constantes as análises do caráter do mexicano, a partir de expressões e palavras: o "pachuco" e a "chingada".

No ensaio de abertura "El pachuco y otros extremos", há uma reflexão de um mexicano frente ao choque cultural com o Outro, o norte-americano. Esse choque foi sentido pelo autor não por experiência de vida acadêmica ou turística: trata-se dos anos de infância vividos nos Estados Unidos como uma espécie de exílio, devido aos problemas políticos de seu pai após a Revolução Mexicana. Por sua vez, o ensaio "Los hijos de la Chingada" apresenta a expressão ("hijo de la chingada"), típica da cultura mexicana, em relação à expressão espanhola ("hijo de puta”).

Ainda no retorno ao México em meados da década de 50, participará das atividades do grupo Poesía en voz alta, criado por Jaime García Terrés, então diretor do Departamiento de Difusión Cultural da Universidade Autônoma do México. A proposta do grupo era promover atividades que incentivassem a promoção da divulgação poética e teatral. Nesse momento, Octavio Paz, que ficou encarregado do segundo programa, em julho de 1956, privilegiou obras de vanguarda e do teatro do absurdo: El canário, de Georges Neveux; Osvaldo y Zenaida, de Jean Tardieu; e El salón del automóvil, de

A correspondência entre Octavio Paz e Haroldo de Campos, em relação à tradução de Blanco, revela uma profunda e profícua preocupação em encontrar expressões, em português, que dessem conta de reproduzir aspectos fônicos e sintáticos. 
Eugène Ionesco. As obras, todas traduzidas, permitiram a apropriação de um conto de Nathaniel Hawthorne, transformado na peça La hija de Rappaccini.

Finalmente, é impossível esquecer a relação da poesia e do pensamento crítico de Octavio Paz com o Oriente. Sua atividade diplomática na Índia e no Japão proporcionou-lhe uma revitalização de poética altamente significativa. Seus estudos sobre a arte japonesa o levam a resgatar as incursões de José Juan Tablada pelo hai-kai, em 1902, com La nao de la China. Esse contato ainda o motiva a traduzir Matsuo Basho e, ao mesmo tempo, construir poemas com as características dos hai-kais (1957) e publicar a prosa poética de El mono gramático (publicado inicialmente em 1974) e os poemas de Ladera Este (1969).

A fim de ilustrar que o trânsito territorial permite o enriquecimento da poesia paziana, veja-se o caso de poemas como os seguintes, presente em Semillas para un himno, cuja primeira edição é de 1954. Os dois poemas têm como base a estrutura do hai-kai. No entanto, não apenas a forma poética lembra as composições japonesas no que tange à métrica tradicional (7-5-7 sílabas distribuídas em três estrofes), mas destacam-se também os efeitos de sentido buscados pelo poeta. Como se sabe, no haiku as dezessete sílabas poéticas se organizam em três tempos: 1) passividade, contemplação de uma cena, de um objeto; 2) ação do eu lírico; e 3) a surpresa, a revelação poética.

Diosa azteca

Los cuatro puntos cardinales

Regresa a tu ombligo.

En tu vientre golpea el día, armado.

Trata-se, evidentemente, de um hai-kai. A temática, no entanto, escapa ao deslumbramento e contemplação do mundo, topos frequente da composição japonesa. O que se identifica é a reflexão crítica sobre a história mexicana. Os tempos, que convergem ao umbigo da deusa asteca, retornam sempre de maneira violenta. Poder-se-ia dizer que o instante de contemplação é substituído por um "instante eterno” de sofrimento.

Outro poema é "Disonancia”, integrante de Himno entre ruinas. Nele, se conserva a reflexão decorrente de uma contemplação inicial e, a partir da observação atenta da natureza, o eu lírico mergulha em pensamentos que o conscientizam de sua posição no mundo.

Disonancia

Los insectos atareados,

Los caballos color de sol,

Los burros color de nube, 
Las nubes, rocas enormes que no pesan,

los montes como cielos desplomados,

la manada de árboles bebiendo en el arroyo,

todos están ahí, dichoso en su estar,

frente a nosotros que no estamos,

comidos por la rabia, por el odio,

por el amor comidos, por la muerte.

A dissonância entre o homem e os demais seres é a temática central desse poema. A consciência do rompimento do homem com a natureza ("todos están ahí, dichosos em su estar, / frente a nosotros que no estamos”) se opõe, na forma e no efeito, à revelação que geralmente é evocada pelos hai-kais.

Além da incorporação dessa composição poética, a presença do Oriente ainda se faz presente nos ensaios que Paz dedica a pensar a poesia japonesa, tal como “Tres momentos de la poesía japonesa”. Além disso, a peça teatral que escreveu, La hija de Rappaccini, possui elementos do teatro $\mathrm{No}^{9}$, mesmo sendo uma obra baseada em um conto de um autor de língua inglesa.

Como se percebe, uma constante na reflexão crítica de Octavio Paz é a preocupação linguística. Seja potencializando a produção poética, seja posicionando-se politicamente acerca dos mais variados assuntos (das relações internacionais às questões estéticas de vários movimentos artísticos) é a crítica que conduz o pensamento paziano. É nesse sentido, aliás, que Alarcón (2009) defende que o discurso crítico do autor de Los hijos del limo

Arranca de considerar la praxis poética o artística como un eje que organiza y ordena los discursos, detrás de los cuales hay apropiaciones de lenguaje que territorializan y desterritorializan las representaciones con nuevas imágenes de la realidad, la cultura y de la sociedad. (ALARCÓN, 2009, p. 132 - o grifo é do original.)

O crítico afirma, ainda, que

El arte se hace crítico de ello [la radicalidad del nuevo modo de construir la tradición cultural] y se muestra en los tópicos que identifican la estética romántica, la cual será revisitada y reterritorializada posteriormente por la vanguardia. (grifo é nosso). (ALARCÓN, 2009, p. 139)

Na peça de Octavio Paz, a presença do Nô se dá, básica e timidamente, por dois recursos cênicos e pela preocupação com a "poesia" dos diálogos. Um dos recursos é utilizado na montagem de duas cenas, a VII e a IX, nas quais predomina a representação por meio da mímica mediada pela personagem O Mensageiro, recurso semelhante aos "espíritos" que tradicionalmente iniciam as peças Nô. 
Com efeito, defendo que é justamente a radicalidade na construção de uma nova tradição cultural e uma práxis poética organizadora do discurso, aliadas ao contato com culturas e estéticas diversas, que promoverá a formulação de uma Poética das Convergências: o pensamento analógico e a tentativa de conciliação dos opostos. Ademais, é justamente essa dimensão de contato com outras literaturas e culturas, que não ocorre inconscientemente, mas a partir de uma reflexão crítica, uma das principais razões para que Octavio Paz seja considerado um escritor extraterritorial. A postura reflexiva em relação à criação poética (característica tipicamente moderna) emerge em poemas, prosas poéticas e ensaios de reflexão sobre a arte em geral e a poesia especificamente.

Segundo Verani (1990), após o florescimento de diversas correntes vanguardistas na década de 20, os anos posteriores apresentarão mudanças significativas nas letras hispano-americanas. A principal será o deslocamento da forma de "agir": predominam posições pessoais em lugar dos grupos. Isso significa que após as vanguardas, no estudo da literatura em língua espanhola na América, devem predominar as posições pessoais em lugar dos grupos. Nesse sentido, é possível afirmar que os processos de extraterritorialidade devem ser compreendidos como parte da consciência crítica na criação artística sem necessariamente significar isolamento do escritor. Pelo contrário, se foi o contato constante com outras culturas, línguas e movimentos que permitiu à literatura hispano-americana se configurar com características próprias, -inclusive diferentes da espanhola - passadas as vanguardas, não seria mais possível buscar o isolamento.

Com efeito, pensar o intelectual e o escritor Octavio Paz e seu lugar no pensamento e na literatura hispano-americana não requer apenas estudá-lo dentro de um processo de modificação dessa literatura, mas considerar principalmente suas constantes mudanças de país, acentuadas pela profissão de diplomata, aliadas à sua ideia central de modernidade, a crítica. Todos esses deslocamentos permitiram-no incorporar e apropriar-se de diversos movimentos e estilos e criar uma arte multifacetada, sem porém uma unidade, típica da busca empreendida pela arte moderna.

Portanto, ao assumir, neste estudo, uma perspectiva histórica da literatura hispanoamericana em geral e de Octavio Paz em particular, vinculou-se o conceito do próprio poeta sobre a modernidade ao de extraterritorialidade cunhado por George Steiner. Com essa aproximação, talvez a melhor síntese a ser elaborada seja a ideia da extraterritorialização como um dos principais processos na sedimentação das obras modernas. Especificamente no caso de Octavio Paz, percebe-se que o poeta mexicano insere-se, inegavelmente, em uma tradição: não a mexicana apenas - o que lhe daria "status" de um americanista. Octavio Paz está inserido em uma tradição hispano-americana e ocidental, 
no sentido de que sua obra é enriquecida com o contato cultural e linguístico com outros países; insere-se, com efeito, em uma tradição de escritores que, na Modernidade, viveram experiências de trânsito territorial, decorrentes de diferentes e diversos motivos.

\section{Referências Bibliográficas}

AlARCóN, R. F. La vanguardia literaria: una instancia formativa del discurso crítico latinoamericano. Revista Literatura y Lingüística, Santiago, n. 18, p. 34-43,2006. Disponível em 〈http://www.scielo.cl/scielo.php?script=sci_arttext\&pid=S071658112007000100006\&ln$\mathrm{g}=$ pt\&nrm=iso\&tlng=es $\rangle$. Acesso $28 \mathrm{dez} .2008$.

. El discurso crítico de Octavio Paz: contextos, desafíos y fundaciones en Latinoamérica de los años 60-80. Santiago: Ariadna, 2009.

PAz, Octavio. Alrededores de la literatura hispanoamericana. In: In / Mediaciones. 3. ed. Barcelona: Seix Barral, p. 1990a, p. 25-37.

. ¿Es moderna nuestra literatura? In: In / Mediaciones. 3. ed. Barcelona: Seix Barral, p. 1990a, p. 39-50.

. Los hijos del limo. 2ed. Barcelona: Seix Barral, 1974.

. Traducción: literatura y literalidad. 3. ed. Barcelona: Tusquets, 1990b.

SCHWARTZ, J. Lenguajes utópicos, "Nwestra ortografía bangwardista”: tradición y ruptura en los proyectos lingüísticos de los años veinte. In: Pizarro, Ana (Org.) América Latina - palavra, literatura e cultura: Vanguarda e Modernidade. V. 3. Campinas: Unicamp / São Paulo: Memorial, 1995.

Steiner, G. "Extraterritorial” In Extraterritorial: Ensayos sobre literatura y la revolución del lenguaje. Trad. Edgardo Russo. Madrid: Siruela, 2002.

. "Los tigres en el espejo”. In: Extraterritorial: Ensayos sobre literatura y la revolución del lenguaje. Trad. Edgardo Russo. Madrid: Siruela, 2002

SCHwARTZ, J. Lenguajes utópicos, "Nwestra ortografía bangwardista”: tradición y ruptura en los proyectos lingüísticos de los años veinte. In: PIZArro, Ana (Org.) América Latina - palavra, literatura e cultura: Vanguarda e Modernidade. V. 3. Campinas: Unicamp / São Paulo: Memorial, 1995.

Ulacia, M. El árbol milenario: un recorrido por la obra de Octavio Paz. Barcelona: Galaxia Gutenberg / Círculo de Lectores, 1999.

VERANI, H. J. Las vanguardias literarias en Hispanoamérica (manifiestos, proclamas y otros escritos). 2. ed. México, DF: Fondo de Cultura Económica, 1990. 